\title{
Un canto sibilino americano (sobre el Discurso en loor de la poesía)
}

El objetivo de este artículo es analizar el Discurso en loor de la poesía, anónimo, escrito a principios del siglo XVII en Perú. Revisamos algunos aspectos como la tradición de defensas de la poesía en la cual se inserta, su relación con la traducción de Ovidio que prologa, realizada por Diego Mexía, o con el procedimiento de la imitatio, así como la clase de reflexión metapoética que tiene lugar en sus versos. Destacamos, asimismo, la construcción de un locus de enunciación americano y de la voz femenina que lo enuncia, en lo cual encontramos un paralelo productivo con la figura mitológica de las Sibilas.

Palabras clave: autora anónima peruana, Diego Mexía, poesía, Ovidio, sibilas

The aim of this article is to analize the Discurso en loor de la poesía, an anonymous text written in Perú at the beginning of the 17th century. We study some relevant aspects of this composition: its inclusion in the poetry's defense tradition, its relation to Diego Mexía's translation of Ovid, the imitatio principles and the metapoetic reflection. We also highlight the construction of an American locus of enunciation and of a feminine voice, which allows us to establish a parallelism with the mythological Sibyls.

Keywords: Peruvian anonymous author, Diego Mexía, poetry, Ovid, sibyls

La traducción de textos de la Antigüedad clásica fue uno de los puntos esenciales del proceso de creación cultural conocido como el humanismo de los siglos XVI y XVII. En ese marco podemos ubicar la Primera Parte del Parnaso Antártico de Obras Amatorias, un libro publicado en Sevilla en I6o8 que ofrecía una traducción al español de las Heroidas y del In Ibin de Ovidio, efectuada por Diego Mexía de Fernangil (Sevilla, España, c. 1565 Potosí, I634). De este traductor sabemos que se hallaba en Lima, al menos desde 1590. Recorrió distintas partes de América como mercader de libros, tarea en la que estaba asociado con Juan de Sarria, librero de Alcalá de Henares. Inició las gestiones para publicar su Parnaso Antártico en I602 (Lohmann Villena 125-126), libro cuyas aprobaciones datan de I604. ${ }^{\text {S Según }}$ explica Mexía en el prólogo titulado "Del autor a sus amigos", había emprendido la tarea de traducir los dísticos de Ovidio en tercetos 
castellanos durante un viaje por tierras mexicanas, adonde había llegado después de vivir en Lima. Del Perú provienen algunos de los paratextos del libro, entre ellos el que alcanzó más celebridad y que aparece entre las tasas, aprobaciones y sonetos de elogio al autor que eran de rigor: nos referimos al extenso poema anónimo titulado

Discurso / En loor de la Poesía, dirigido al Autor, i compues/to por una senora principal d'este Reino, mui ver/sada en la lengua Toscana, i Portuguesa, por cuyo / mandamiento, i por justos respetos, no se escrive / su nombre; con el qual discurso (por ser / una eroica dama) fue justo / dar principio a nuestras / eroicas epistolas) ${ }^{2}$

Este extenso poema será agradecido por el traductor de Ovidio en un soneto, dedicado a la "matrona [h]onor d'el mismo Apolo", "Deidad de nuestro Polo" que merecería, según Mexía, ser adorada por las nueve musas. El $D L$ está compuesto por 808 versos, organizados en tercetos endecasílabos de rima encadenada, la terza rima del Dante, el mismo metro usado por Mexía para su versión de las Heroidas.3 Una forma métrica que los tratadistas reconocían como esencialmente culta, propia de temas graves o dignos, como la solemnidad del homenaje o los temas doctrinales, dos vertientes que confluyen en el $D L$ (Cornejo Polar, Discurso 6r).

La crítica ya ha señalado que, por su tema y título, el $D L$ se inscribe en la extensa tradición de elogios o defensas de la poesía que el humanismo renacentista había codificado a partir de la recuperación de los clásicos. Desde la antigüedad, existieron textos que, en líneas generales, respondían al propósito de la laudatio artium. Los elogios antiguos de las artes, entre ellas la poesía, contaban con ejemplos célebres como el elogio a la música de Plutarco, el Pro Archia de Cicerón o algunos Carmina de Horacio.4 Pero no eran, necesariamente, defensas - exceptuando, quizás, el de Cicerón. Hacer de la laudatio, el elogio, una defensa fue un rasgo que se agregó en la época del Renacimiento, cuando tanto las poéticas como los planes de estudio de inspiración humanista se enfrentaron a la tradición escolástica. El influjo del humanismo renacentista en la reflexión metapoética es inexcusable en cualquier lectura del $D L$, al punto de que Giuseppe Bellini considera que este poema es un producto algo tardío del italianismo del siglo XVI (I4).

El $D L$ se puede encuadrar, a su vez, en la tradición apologética y de reflexión metapoética que celebra la productividad cultural americana, una tradición que cuenta, entre sus obras más significativas con el Compendio apologético en favor de la poesía, incluido en la primera edición de la Grandeza mexicana de Bernardo de Balbuena (México, I604), la Invectiva apologética de Hernando Domínguez Camargo (Nueva Granada, I652) y el 
célebre Apologético en favor de Don Luis de Góngora de Juan de Espinosa Medrano, el Lunarejo (Cuzco, I662). Podemos agregar a esta serie algunas secciones de la célebre Respuesta a Sor Filotea de la Cruz con la que Sor Juana cierra casi el siglo y se autodefiende mientras defiende, también, a la poesía (México, I69i). Pero dentro de este corpus, la peculiaridad del $D L$ es que está escrito en verso, con lo cual la defensa de la poesía es doble, de iure y de facto.

Aunque no se trata, estrictamente hablando, de una preceptiva, Antonio Cornejo Polar ha puesto este poema en relación con las preceptivas españolas de los siglos XVI y XVII.5 Para Trinidad Barrera, se trata de "una de las escasas poéticas coloniales del virreinato" (II2). Elena Calderón de Cuervo, por su parte, considera que este texto representa la primera filosofía poética de las letras coloniales y que pone en evidencia el valor esencialmente humanístico de las producciones literarias americanas, a diferencia del marcadamente cortesano barroco peninsular (7).

Como ya dijimos, las defensas de la poesía renacentistas se enmarcaban en un contexto más amplio, el de la defensa de los estudios humanistas, cuyo eje se había desplazado de las letras sagradas a las profanas - sin que ello implicara excluir las primeras, huelga decirlo. Fue a partir del humanismo renacentista y de Petrarca que las "alabanzas de la poesía" adquirieron un nuevo sentido, porque no sólo se trataba de una defensa de la poesía frente a otras modalidades genéricas, temáticas y discursivas, sino que la poesía también era sometida a una redefinición. En figuras como Boccaccio, el arte poética se convertía en "un concepto amplio que tendía a abarcar no sólo toda la literatura sino todas las ciencias, artes y estudios humanos, porque el poeta culto tenía que saberlo todo" (Rivers I2), una misión mucho más exigente que la conferida a la poesía por la educación medieval, donde se encontraba ligada a la enseñanza de la gramática y la retórica. Por otro lado, al alabar la poesía, Boccaccio proponía una defensa del estudio de la literatura pagana antigua, un nuevo programa de educación literaria que sería esencial al humanismo.

De allí el lugar central de la traducción para alcanzar los objetivos del humanismo: exigía regresar a los textos originales, ejercer una actitud crítica hacia ellos, establecer versiones fidedignas de los escritos antiguos y era una forma de difundir los conocimientos. En el Virreinato del Perú había nacido el responsable de una traducción importante para el Renacimiento: nos referimos a la versión del Inca Garcilaso de la Vega de los Diálogos de amor de León Hebreo (Jehudah Abarbanel), obra esencial para la difusión de ese neoplatonismo que, al decir de Ángel Rama, "sirvió 
de cauce cultural al empuje capitalista ibérico" (37). La traducción tampoco fue una tarea secundaria para los letrados residentes en Lima: antes del Parnaso Antártico, por ejemplo, Enrique Garcés había traducido a Petrarca y a Camoes (Rose 89). En cuanto a Ovidio, fue uno de los autores más traducidos desde la Antigüedad, clave en la difusión de la mitología clásica en los siglos XVI y XVII, gracias, sobre todo, a sus Metamorfosis. Gutierre de Cetina había publicado una traducción de las Heroidas en México a finales del siglo XVI, pero la edición de Mexía tuvo mayor éxito, y se reeditó hasta el siglo XX. ${ }^{6}$

Mexía de Fernangil sigue claramente una línea, si no enteramente alegórica, moralizadora y didactista en su versión de Ovidio, pues acompaña su traducción de comentarios o epígrafes que contextualizan las epístolas y, las más de las veces, les otorgan un sentido moral. Este procedimiento calza perfectamente con la noción de traducción imperante en el Renacimiento, cuando "las traducciones eran, más bien, versiones que ampliaban, explicaban, cambiaban o suprimían numerosos fragmentos del original" (Castany Prado 6). Una prueba de esta concepción la tenemos en el hecho de que la edición de 1608 se publicó bajo el nombre del traductor, Mexía, y que en ella, el paratexto que oficia como prólogo se titula "El autor a sus amigos", mientras que en ediciones posteriores, como la de i884, el texto se publica consignando como autor a Publio Ovidio Nasón y el mismo prólogo - uno de los pocos paratextos que se conservan, pues la mayoría de poemas laudatorios desaparecen, incluido el $D L$ - pasa a llamarse "Advertencia del traductor". En síntesis, la traducción era, para el humanismo renacentista, otro ejercicio compositivo al amparo de la imitatio. Una imitatio que podía proyectarse del texto a la peripecia vital de su contexto: José Antonio Mazzotti ha señalado cómo ciertos episodios biográficos de Mexía, relatados en el prólogo, cobran valor literario si se los compara con típicas secuencias de la novela bizantina y de toda la narrativa de peregrinos. Por ejemplo, la tormenta que altera el destino de los personajes y que, en este caso altera el periplo vital del traductor, quien entretiene su camino a México, luego de un naufragio, traduciendo a Ovidio, el mismo autor que en los Tristia había hecho del naufragio y del destierro un tópico central.7 Para este crítico, Mexía se autorrepresenta como "un Ovidio español en el destierro americano, donde llevaría, tal como hizo el sulmonés, la lengua imperial a las mayores alturas de expresión" (xxxii, nota 39). Se trata, en definitiva, de un juego de espejos desatado por las operaciones de reescritura y traducción de la tradición clásica: entre la biografía de Ovidio, el prólogo del traductor y el mismo $D L$, varios de cuyos pasajes están orientados a la moralidad y el didactismo. Ecos que se concretan en diversas formas dialógicas, desde el intercambio 
epistolar que ficcionalizan las epístolas ovidianas - aunque la mayoría no tengan respuesta - hasta las vinculaciones temáticas y retóricas entre el $D L$ y la traducción de las Heroidas que prologa. ${ }^{8}$ Barrera, por ejemplo, ha señalado que hay un explícito apoyo de Mexía de la anónima poetisa al darle el lugar de antesala de su traducción y equipararla a sus heroicas damas:

No es extraño el apoyo que le presta Mexía si tenemos en cuenta que como admirador de Ovidio que era, debía tener muy en cuenta que el sulmonés, en su Ars Amandi, aconsejaba a las mujeres la lectura de los poetas, curiosa línea de contacto entre tres puntos, Mexía, la dama y, en medio, Ovidio, justamente en sus Heroidas que privilegian el papel de la mujer. Papel muy distinto al que defendiera San Pablo, sobre el silencio que deben guardar las mujeres. (II7)

Discrepando de Cornejo Polar, quien no encuentra relación entre el $D L$ y la traducción de las Heroidas hecha por Mexía (40-4I), Mazzotti ha señalado la necesidad de analizar los paralelos y variaciones estilísticas entre la traducción y su paratexto, los que revelan, al menos, una lectura cuidadosa por parte del sujeto del $D L$ de la traducción de Mexía (xxii, nota i9). Sólo a título de ejemplo, mencionemos que en la epístola octava, Ermione, prisionera de Pirro, le ruega a su primer esposo, Orestes, que la rescate, porque "fuerzas de mujer no pueden nada" (Ovidio, Heroidas II 9 ), un verso cuyo eco parece estar en el $D L$, cuando afirma que la empresa de defender a la poesía excede las fuerzas de una mujer. 9

Por otro lado, si el $D L$ teologiza o moraliza la poesía, como veremos más adelante, no otra cosa hace Mexía con su interpretación de las historias narradas en las Heroidas. Io Señala que agrega información moral a los textos siguiendo a Horacio y Aristóteles y en la Dedicatoria a Don Juan de Villela, Oidor en la Real Audiencia de Lima, afirma: “...cuando estas epístolas no merecieren el nombre de Ovidianas, por su umilde traduzion, se les debe el de Cristianas, por la onestidad, y moral dotrina, con que las é traduzido" (Mexía). En la misma línea, sostiene que "esta obra muy justamente tiene parte en la moral filosofía que los griegos llaman Ética, pues las virtudes y los vicios con tan eficaces ejemplos nos enseña" (Mexía en Ovidio, Heroidas XIV). En la "Vida de Ovidio" otro de los paratextos de la traducción, se dice que el autor latino es digno de imitación "de los cristianos poetas" (Mexía en Ovidio, Heroidas XVIII).

La comparación de los amores inmorales con los pecadores de las Sagradas Escrituras es explícita, cuando se aclara que su función es la del ejemplo adoctrinador. En el epígrafe de la epístola cuarta, verbigracia, 
dirigida por Fedra a Hipólito, Mexía resume cómo Fedra se enamoró de su hijastro y agrega:

Fedra enamorada de su entenado, y rendida a su apetito, como de palabra no se atreviese por la gravedad del pecado a descubrirle su pena, le escribe esta carta, donde le persuade a su bruta y totalmente ilícita voluntad. Por la cual se verá la libertad y desenvoltura que tiene la mujer que pierde el temor a Dios y la vergüenza al mundo. (Ovidio, Heroidas 44)

También podemos observar, en la edición de 1608 , una suerte de colofón moralizante - que desaparece en la de i884, por cierto - donde se narra el suicidio de Safo, olvidada de Faon: “... Por cuyo fin, y por casi todos los demás de estas Epístolas vemos claramente, cómo de un amor torpe, y de una infame, y desordenada vida, de ordinario se siguen arrebatadas, y lamentables muertes" (Mexía, Parnaso 240).

Otro caso bien notable es la introducción de la epístola sexta, "De Isipile a Jasón", donde Mexía juzga necesario explicar la fábula del vellocino de oro: el rey poseedor de la piel del vellocino, conocedor de una profecía que vaticinaba que moriría cuando un navío llegado de lejanas tierras se llevase la preciada piel, "dio en una horrenda crueldad, que fue sacrificar todos los huéspedes y forasteros que venían a su reino, que era el fruto que el demonio, padre de la maldad, pretendía y pretende de los idólatras miserables" (Ovidio, Heroidas 76). Se actualiza aquí el sentido del mito, cuando se afirma que el demonio "pretendía y pretende" engañar, en una frase que evoca las múltiples acusaciones de idolatría que pesaban por entonces sobre los indígenas americanos.

DOS ENIGMAS: LA AUTORA DEL DISCURSO Y LA ACADEMIA ANTÁRTICA

Simultáneamente elogio y defensa de la poesía, el $D L$ nos ofrece algunos aspectos en los que vale la pena detenerse. En primer término, la peculiaridad de que la voz enunciadora, aunque anónima, esté configurada como una voz femenina. Sobre esta cuestión, el problema de la autoría ha sido medular en la crítica sobre el poema. Fue Marcelino Menéndez y Pelayo quien le asignó el nombre de Clarinda a su anónima autora, tomando el nombre de aquella que, según el propio $D L$, inspiraba los versos de uno de los miembros de la Academia Antártica, Juan de Salcedo Villandrando. Mencionada una sola vez en el poema y en tercera persona, la identificación entre la autora y Clarinda, que al decir de Mazzotti podría no haber sido más que un tema de composición (xxxiv), es una ligereza que se perpetuó, en gran medida porque Ricardo Palma repitió la identificación

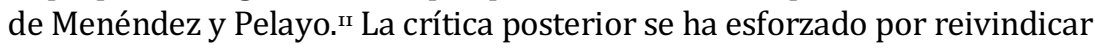


la existencia de una autora mujer, insistiendo en darle entidad biográfica a esta Clarinda, que ha devenido en una "seudoidentidad" para hacer referencia a quien compuso el $D L$ (Mazzotti xxii). Lo que es innegable es que el sujeto poético del $D L$ se atribuye rasgos femeninos y defiende un lugar de enunciación americano.

Si se acepta la existencia de lo que Jorge Cornejo Polar ha denominado el "primer grupo orgánico de poetas" de Lima (37), a saber, la conocida como Academia Antártica, el $D L$ incluiría entre sus méritos el ser el primer registro cultural de dicho grupo. Según los indicios analizados por Alberto Tauro y, más recientemente, por Sonia Rose, esta Academia habría funcionado durante la última década del siglo XVI y la primera del XVII. Su función habría sido la de un ámbito de sociabilidad que convocaba a los poetas y escritores del lugar, un espacio de particulares que formaron una corporación en tiempos en que el ejercicio de la letra era tanto signo de cortesanía como medio de movilidad social en sociedades en proceso de burocratización. Luego del período de organización del Virreinato del Perú, marcado por la figura del virrey Francisco de Toledo y la instalación de la Universidad de San Marcos, había tenido lugar una etapa de consolidación, en la cual se destacaron las figura de Santo Toribio de Mogrovejo - segundo arzobispo de Lima, el mismo que concretó el Tercer Concilio Limense - y la de don Juan de Mendoza y Luna, marqués de Montesclaros. Este último promovió el florecimiento de las letras que, al decir de Elena Calderón (20-2I), tendría su resultado más visible en esta "Antartica Academia" (v. I48), cuyos miembros - una veintena - son enumerados en el $D L$.

La construcción de un espacio como las academias surge, en el caso limeño, por las exigencias de reconocimiento, legitimación y valoración de las élites de una ciudad que buscaba competir con la otra gran ciudad virreinal, México, y de una región que, hasta ese momento, el imaginario europeo sólo reconocía como fuente de riquezas materiales y extracción de metales (Rose 85-87). Sobre este aspecto en particular, el $D L$ es explícito: en sus versos se menciona a Duarte Fernández, de quien se dice "que vale mas su vena, que las venas / de plata, qu'alli puso el cielo amigo" (vv. 53053I), y en el mismo prólogo de Mexía, se explica que el cultivo de tareas espirituales, como la poesía y la traducción, se enfrentaba a la búsqueda de satisfacciones materiales dominante en la empresa americana:

...en estas partes se platica poco de esta materia, digo de la verdadera poesía y artificioso metrificar, que de hacer coplas a bulto, antes no hay quien no lo profese, porque los sabios que de esto podrían tratar sólo tratan de interés y ganancia, que 
es a lo que acá los trajo su voluntad; y es de tal modo, que el que mas docto viene se vuelve más perulero ... (Mexía en Ovidio, Heroidas XII; Mexía, folio 4)

La cuestión de la justificación, a la luz de la moral cristiana e imperial, de la escritura, está presente ya desde otro de los paratextos que conviven con el $D L$ en el Parnaso Antártico. En la dedicatoria a Don Juan de Villela, Mexía ofrecía su labor traductora como una muestra de los beneficios de la colonización española en América:

Mas es justo, que se entienda, que habiendo [España] con tanta gloria pasado sus columnas con las armas, de los límites, que les puso Alcides, también con ellas pasó las ciencias, y buenas artes, en las cuales florecen con eminencia en estos reinos muchos excelentes sujetos. (modernizo la grafía)

A la mención de la "Antártica Academia" (v. I48) se suma la de eventos históricos contemporáneos, como las interminables guerras del Arauco, todo lo cual colabora en una relocalización de la geografía poética, que se ve desplazada a América. Indudablemente el pasaje más notable al respecto es aquel en el cual la voz enunciadora, en la clásica invocación a Apolo y a las musas para que le concedan su inspiración, exclama: "Aquí Ninfas d'el Sur venid ligeras, / pues que soy la primera qu'os imploro, / dadme vuestro socorro las primeras" (vv. 22-24). Es decir que no está convocando a las musas grecolatinas, a las Pimpleides ni a las musas del Helicón, sino a unas novedosas Ninfas del Sur, reescribiendo la tradición clásica y humanista en función de un locus de enunciación americano y actual. En la alusión temporal "soy la primera que os imploro", el llamado del poeta - la poetisa, en este caso - parece conferir existencia a esas musas sudamericanas. Ese locus de enunciación no se encuentra, en consecuencia, ni desterritorializado ni en la acronía del mito y su función es invitar a la poesía a desplazarse de Europa a América, en un gesto que repetirá, siglos después, una figura como Andrés Bello en su Alocución a la poesía, pero que aquí tiene el sentido de la translatio studii asociada a la expansión del imperio.

La cuestión de la localización de la génesis poética no es algo menor, tal como lo testimonia el mismo poema cuando pasa revista a la geografía mitológica donde habitaban las musas o cuando alude a la pelea entre las ciudades griegas por ser declaradas el lugar de nacimiento de Homero: "Fu'en montes consagrados colocada, [la poesía] / en Helicon, en Pimpla, i en Parnaso, / donde a las Musas dieron la morada" (vv. 304-306), o bien: "Siete ciudades nobles, florecientes / tuvieron por el ciego competencia, / 
que un bue[n] Poeta es gloria de mil ge[n]tes" (vv. 382-384). En el caso americano, fe cristiana y poesía llegan de la mano de la conquista española:

Que como dio el Dios Marte con sus manos

al Español su espada, porque el solo

fuesse espanto, i orror de los Paganos:

Assi tambien el soberano Apolo

le dio su pluma, para que bolara

d'el exe antiguo a nuestro nuevo Polo. (vv. 469-474)

La espada y la pluma se vinculan nuevamente, y la potenciación poética de la lengua castellana es presentada como otra proyección de las grandezas del imperio, en la misma línea en que Cicerón, apoyándose en argumentos de orden lingüístico, había defendido a Arquías cuando se objetaba su acceso a la ciudadanía romana porque escribía en griego: el arpinense refutaba ese argumento explicando que el latín no había alcanzado la difusión geográfica del griego, que "se lee en casi todos los países", a los cuales permitía llegar la fama y gloria del pueblo romano (70).

MUJERES DOCTAS Y EL DON DIVINO DE LA POESÍA

Es realmente llamativo que, de todas las voces del círculo letrado afín a Mexía, sea la de un sujeto femenino la que preludia este Parnaso Antártico y se erija en defensora de la poesía. Sobre todo porque esa voz va a construir una genealogía en la que insertarse, que antecede en varias décadas al célebre linaje de mujeres doctas armado por Sor Juana Inés de la Cruz en su Respuesta a Sor Filotea. Entre las mujeres bíblicas que han "cantado" aparecen desde Eva hasta la Virgen María, pasando por Judit, y de las paganas, se rescata a Safo, la latina Proba Valeria y las proféticas sibilas. Desde el momento en que la laudatio se desplaza hacia la defensa, hay una dimensión épica en el poema que, en consonancia con el material ovidiano que prologa, convierte a la mujer poeta no solo en una voz inspirada o erudita, sino fundamentalmente en una heroína. En relación con esto, el linaje de poetisas heroicas cumple la función, al decir de Alicia de Colombí-Monguió, de "probar la existencia de una capacidad [poética] que, de serle negada [a la mujer], la exiliaba de facto de la comunidad humanista" (29). De allí que el origen de la poesía y de la capacidad poética femenina se fundan en un hipotético génesis que nos retrotrae al mismo Adán:

Quien duda qu'advertiendo allá en la mente las mercedes, que Dios hecho l'avia, 
porque le fuesse grato, y obediente:

No entonasse la voz con melodía,

i cantasse a su Dios muchas canciones,

y qu'Eva alguna vez le ayudaría. (vv. 133-138) ${ }^{12}$

Este momento inaugural de la poesía que se confunde con el origen de la humanidad, enfatiza la dimensión divina del don de la poesía que, según este mismo argumento, fue desde el principio patrimonio compartido por hombres y mujeres. Por eso la hablante advierte: "Mas sera bien, pues soy muger, que d'ellas / diga mi Musa, si el benino cielo / quiso con tanto bien engrandecellas" (vv. 42I-423).

La concepción de la poesía como don divino asociado con una voz femenina y un sujeto erudito tiene un punto de anclaje en la figura de las sibilas, mencionadas en la genealogía de mujeres doctas / poetas arriba sintetizada. Sobre la figura de las Sibilas, recordemos brevemente que se trataba de profetisas itinerantes - a diferencia de las pitonisas - y que debían sus dotes mánticas a Apolo.13 Este tipo profético, originado en el Asia Menor, tuvo una exitosa descendencia en el mundo grecorromano que fue resignificada en la era cristiana. Varrón, en el siglo I a.C., había elaborado un catálogo de diez Sibilas. De todas ellas, Virgilio consagró literariamente a la de Cumas, en lo cual fue seguido por Ovidio. Los escritos de Varrón sobre el tema - hoy perdidos - fueron recogidos por Lactancio en sus Divinae Institutiones, en el siglo III d. C. El cristianismo tomó de la figura de las Sibilas un rasgo que permitía ponerlas en paridad de condiciones con los profetas veterotestamentarios, al entender que cumplieron el rol de anunciar al verdadero Dios en un mundo politeísta, y que habían llegado a profetizar la llegada de Cristo. Del "canon sibilino" (Buisel IO4) que Lactancio difundió, basado en Varrón, el cristianismo rescató especialmente a las Sibilas itálicas de Cumas y Tíbur, y a la sibila griega de Eritrea. San Agustín, por ejemplo, dedica dos capítulos de su libro La ciudad de Dios a las Sibilas de Cumas y a la de Eritrea.14 Durante el Renacimiento, la traducción de Marsilio Ficino del Corpus Hermeticum reactualizó las interpretaciones de autoridades como Lactancio y San Agustín, quienes habían avalado, además, la hipótesis de que Hermes Trismegisto, el supuesto autor del Corpus, había profetizado el advenimiento del cristianismo. Lactancio, en particular, consideraba que la sabiduría pagana, cuyas fuentes creía encontrar en los Hermetica, podía ser utilizada para demostrar la verdad del cristianismo. Aunque escritos en los siglos II y III de la era cristiana, los textos del Corpus Hermeticum se consideraron, hasta el Renacimiento, de origen egipcio y se les atribuía una fecha de composición muy anterior a la cultura clásica grecorromana. Los 
textos herméticos fueron correctamente datados por Isaac Casaubon, como de redacción poscristiana, en I6r4, pero su influjo y su afán de conciliar el cristianismo con la magia y una presunta antigua filosofía perdurarían por años. El hermetismo neoplatónico renacentista intensificó así la legitimación, por parte del cristianismo, de las Sibilas, que llegaron a ser pintadas en algunas salas vaticanas y aparecen representadas junto a Hermes Trismegisto, por ejemplo, en un notable mosaico de la catedral de Siena. En sintonía con este proceso de apropiación cultural, ya desde el siglo XVI las Sibilas habían emigrado a América, inaugurando una tradición iconográfica singular, con las peculiaridades propias de cada región (Buisel I08). .5

Como dijimos líneas arriba, las Sibilas aparecían, en la literatura clásica, en la obra del mismo autor que Mexía estaba traduciendo, pues el libro XIV de las Metamorfosis de Ovidio narraba la llegada de Eneas a Cumas donde, gracias a la intervención de la Sibila habitadora de esas costas, había logrado visitar el Averno y encontrarse con la sombra de su padre. Luego de ese episodio, la misma Sibila le relató a Eneas cómo había adquirido una suerte de inmortalidad aunada al ejercicio de la profecía y al rasgo moral de la castidad: intentando seducirla, Febo había prometido otorgarle el don que ella eligiera, la Sibila pidió entonces vivir tantos años como los granos de polvo que había atrapado en su puño, aunque olvidó solicitar que esos años fuesen de juventud. Por ello, se encontraba transitando los últimos trescientos de los mil años en que estaba cifrado el tiempo de su vida, en un cuerpo que se inclinaba a la vejez y la disolución final, pero al cual lograría sobrevivir gracias a su voz:

Tiempo llegará en que la larga vida hará pequeño este cuerpo

ahora tan esbelto, y mis viejos miembros, consumidos,

seducidos se verán a casi nada, y no parecerá que yo he gustado

y he sido amada por un dios; y quizás el mismo Febo

no me reconocerá o negará haberme querido: tanto dirán que cambié;

$\mathrm{y}$, para todos invisible, no obstante, por mi voz

seré reconocida, porque los hados me dejarán la voz.

(Ovidio, Metamorfosis, XIV, vv. I47-153, 515)

El pasaje del $D L$ en que aparece la mención a las Sibilas compendia una serie de significaciones. Veamos:

De las Sibilas sabe el universo

las muchas profecias, que escrivieron

en metro numeroso, grave, i terso. 
Estas d'el celestial consejo fueron

participes, i en sacro, i dulce canto

las Febadas oraculos dixeron.

Sus vaticinios la Tiresia Manto,

de divino furor arrebatada

en versos los cantó, poniendo espanto.

Pues que diré d'Italia, que adornada

oy dia se nos muestra con matronas,

qu'en esto eceden a la edad passada.

Tu o Fama en muchos libros las pregonas,

sus rimas cantas, su esple[n]dor demuestras,

i assi de lauro eterno las coronas.

Tambien Apolo s'infundio en las nuestras

i aun yo conozco en el Piru tres damas,

qu'an dado en la Poesia eroicas muestras. (vv. 442-459)

Tenemos aquí una mención al colectivo de las Sibilas, que versos antes fue precedida por la referencia a Damófila, la Sibila de Cumas (v. 432), como parte de ese catálogo de voces femeninas en las cuales "s[e] infundió" el don de Apolo, el "divino furor" que es, a la vez, inspiración poética y profética. Como la adivina Manto, las sibilas son ejemplos de una adivinación por entusiasmo, es decir, por influjo de la divinidad. Pero además de sus cualidades mánticas, el $D L$ enfatiza el hecho de que todos sus oráculos o profecías eran pronunciados o escritos - como dice el verso 443 en clara alusión a los denominados Libros Sibilinos - en "metro", en "versos" o, más contemporáneamente, en las "rimas" de esas "matronas" italianas que "oy dia" son inspiradas por Apolo. Hacia el final de los versos citados, éste, divinidad tutelar tanto de la poesía como de la profecía, extiende su influjo a las poetas americanas y al sujeto enunciador del mismo $D L$, quien dice, en un pasaje autorreferencial: "Soi parte, y como parte me recelo, / no me ciegue aficion, mas dire solo / que a muchas dio su lumbre el Dios de Delo" (vv. 424-426). Ese "soi parte" transforma la genealogía de mujeres doctas y poetas, paganas y cristianas, no sólo en una defensa de la poesía sino en una justificación de su ejercicio por parte de un sujeto que se representa como femenino. Las "Ninfas del Sur" - figuras míticas emparentadas, también, con el culto de Apolo y las Sibilas - se transforman, en consecuencia, en el canal de transmisión del furor divino, poético y profético, hacia un sujeto femenino y sudamericano. ${ }^{16}$ 
LA POESÍA COMO ÉPICA DEL CONOCIMIENTO

Precisamente en este punto necesitamos volver a pensar en la clase de defensa que esta dama anónima hace de la poesía. Porque si en el humanismo esa defensa había requerido de una energía digna de una empresa bélica, realmente ya no tenía el mismo sentido a comienzos del siglo XVII, cuando hacía más de un siglo que el curriculum humanista había triunfado en Europa (Colombí-Monguió 42). Sin embargo, el proceso cultural de la Contrarreforma había reavivado el conflicto entre cristianismo y cultura pagana, y la fórmula en la que Petrarca había sintetizado la cultura humanista - sabiduría platónica, dogma cristiano y elocuencia ciceroniana - parecía requerir de una nueva "teologización de la poesía" que de algún modo limitara o reorientara el neopaganismo renacentista (Pérez- Blanco 216, nota 9), en un tiempo en que las poéticas acusaban el impacto tridentino y el humanismo ensanchaba su vertiente más devota. Luis Jaime Cisneros ha rastreado la presencia de temas bíblicos en el $D L$, encontrando que siguen, incluso, el orden en que están presentados en la Biblia, desde el Génesis hasta los Evangelios (197).

Es en este marco que la poesía, don divino y compendio de toda ciencia humana, como lo quería el neoplatonismo, reforzaba su atributo de ser un medio de conocimiento teológico, que nacía y volvía del mismo Dios: 17

Quiso [Dios] que aqueste don fuesse una fuente

de todas cuantas artes alcançase [el hombre]

i mas que todas ellas ecelente.

De tal suerte qu'en el se epilogase

la umana ciencia, i ordenó qu'el dallo

a solo el mesmo Dios se reservase.

Que lo demas pudiesse el enseñallo

a sus hijos, mas que este don precioso

solo el que se lo dio pueda otorgallo.

Que don es este? quien el mar grandioso

que por objeto a toda ciencia encierra

sino el metrificar dulce, i sabroso? (vv. 88-99)

Como ciencia infusa que nace de Dios, la poesía exige que sus practicantes sean hombres o mujeres doctos: "I aquel qu'en todas ciencias no florece, / i en todas artes no es exercitado, / el nombre de Poeta no merece" (vv. Io6IO8). La poesía es defendida, en consecuencia, porque ofrece una doctrina de la vida, porque Dios, para encauzar a los que se habían apartado de sus enseñanzas, 
Dio al mundo (indino d'esto) los Poetas

a los cuales filosofos llamaron

sus vidas estima[n]do por perfetas.

...

Conocio el mundo en breve los provechos

d'este arte celestial de la Poesia,

viendo los vicios con su luz deshechos

Crecio su onor, i la virtud crecía

en ellos, y así el nombre de Poeta

casi con el de Iove competía.

Porqu'este ilustre nombre s'interpreta

hazedor, por hazer con artificio

nuestra imperfeta vida más perfeta. (vv. 259-288)

El poeta, el hacedor, cumple, entonces, un rol civilizador. Y como la poesía es un don divino - sin que ello signifique que la vena pueda prescindir del arte -, la anónima autora del $D L$ es también una hacedora, la suya es una voz que colabora en el proceso civilizatorio. Algo que queda bastante en evidencia cuando menciona a uno de los más célebres miembros de la Academia Antártica, Pedro de Oña, el autor de El Arauco domado (1596), pues, según el sujeto poético, la única "doma" de los araucanos era la que habían logrado los versos de Oña y no las armas de los españoles:

Con reverencia nombra mi discante

al Licenciado Pedro d’Oña: España

pues lo conoce templos le levante.

Espiritu gentil doma la saña

d'Arauco (pues co[n] hierro no es posible)

con la dulçura de tu verso estraña. (vv. 550-555)

Si se pone en relación un pasaje como este con lo que dicen algunos versos anteriores, el sistema de pensamiento que legitima la función de la poesía se torna más claro. En el relato sobre la historia humana que encontramos en los primeros versos del $D L$, se explica que la humanidad, tras caer en el pecado, se había dividido en dos. Una minoría siguió a Dios y tuvo acceso al conocimiento de lo verdadero: "La que siguió de Dios el vando, i seña, / toda ciencia eredó, porque la ciencia / fundada en Dios al mesmo Dios enseña" (Vv. I5I-I53). Respecto de la otra "parcialidad" (Vv. 24I), moralmente perdida, Dios no la abandonó y le dio a los poetas, para encarrilarla: 
Estos mostraron de naturaleza

los secretos; juntaron a las gentes

en pueblos, i fundaron la nobleza.

Las virtudes morales ecelentes

pusieron en preceto; i el lenguaje

limaron con sus metros eminentes.

La brutal vida, aquel vivir salvage

domesticaron, siendo el fundamento

de pulicia en el contrato, i trage. (vv. 259-273)

Es decir, que la civilización es presentada como un efecto de la poiesis, arte y ciencia que permite superar el "vivir salvage" y adquirir normas de "pulicia", gracias al dominio del lenguaje que los poetas "limaron" y que les permitió, entre otras cosas, poner les leyes morales "en preceto".

La poesía ostenta, en consecuencia, una dimensión heroica que la acerca a los éxitos de la guerra: ya Cicerón afirmaba que el poeta Arquías, aunque nacido en una colonia griega, merecía la ciudadanía romana porque había celebrado la guerra contra Mitrídates. En ese discurso ciceroniano, una de las más evidentes fuentes del $D L$, el ejercicio de la poesía con fines laudatorios respecto de la república - es decir, la poesía épica - se confunde con el derecho a la ciudadanía: "Cuando estas hazañas son exaltadas por el genio de los poetas, por su medio se extiende la fama del pueblo romano" (68).18 En el $D L$, el tono y léxico épico continúan cuando se afirma que la defensa de la poesía es una "hazaña" difícil de soportar "en ombros de muger que son d'araña" (vv. 52-54), o cuando el sujeto poético explica que se ha convertido en "soldado" forzada por las circunstancias:

Mas el grave dolor que m'a causado ver a Elicona en tan umilde suerte, me obliga a que me muestre tu soldado.

Que en guerra qu'amenaça afrenta, o muerte, será mi triunfo tanto más glorioso cuanto la vencedora es menos fuerte. (vv. 55-60).

La concepción de la poesía como don divino, ya mencionada en la alusión al mito de Apolo y las Sibilas, se desplaza a una interpretación afín a la teología cristiana cuando se explica que Dios, luego de crear al hombre, "imagen milagrosa" (v. 74) de sí mismo, que concentra "...de todo lo criado 
/ la suma, i lo mejor de cada cosa." (vv. 76-78), le había otorgado el don de la poesía, que compendiaba toda la "vmana ciencia" (vv. 79-III).

Desde luego, la idea de que toda ciencia cierta proviene de Dios era medular al pensamiento cristiano, pero la concepción de la poesía como cifra del conocimiento tuvo un momento de énfasis en el humanismo renacentista y, en particular, en la doctrina neoplatónica. Mabel Moraña sostiene que la concepción central del discurso es, precisamente, la neoplatónica, a la cual se suman elementos de otras vertientes: aristotélicos, ciceronianos, etc. (Viaje 453). Ya Cicerón afirmaba que "todas las artes que conciernen a la cultura del hombre tienen un cierto vínculo común y están unidas entre sí por una especie de parentesco" (48). El $D L$ advierte, además, acerca de la imposibilidad de que exista un "poeta consumado" (v. III), porque eso equivaldría a decir que puede existir un ser humano capaz de alcanzar el conocimiento total, un aspecto que lo homologaría a Dios. ${ }^{19}$ El detalle no es menor, y se encuentra realzado, incluso, tipográficamente, en la edición príncipe, donde aparece una marca en forma de mano, señalando la importancia de este pasaje.

La clase de conocimientos que involucra la poesía se relaciona con dos cuestiones conexas: I/ su eventual utilidad, 2/ la clase de imágenes y la retórica convocadas en la poesía. Respecto de lo primero, el $D L$ es muy claro. Si cada arte o ciencia es útil en algo al hombre, la poesía, en tanto que suma de las artes y ciencias, será de la máxima utilidad:

Cada arte importa, importa cada ciencia, porque de cada cual viene un provecho, qu'es el fin a que mira su existencia... Es la Poesia un piélago abundante, de provechos al ombre: i su importancia no es sola para un tiempo, ni un insta[n]te." (vv. 658-666) 20

En cuanto al segundo aspecto, la figuración poética tenía un escollo que salvar en lo referente al uso de las imágenes paganas, tan caro al humanismo renacentista, como las figuras de los dioses grecorromanos o de las sibilas. En el $D L$, el problema es resuelto alegóricamente cuando se afirma que la Poesía se adorna con las imágenes paganas para realzar la belleza que Dios le había conferido, en un procedimiento afín al de la decoración de los templos católicos:

Pues como? En templo santo, en santo dia, i entre gente Cristiana d'almas puras, i donde está la sacra Eucaristia: 
Se permiten retratos, i figuras

de los Dioses profanos, i de aquellos,

qu'estan ardiendo en cárceles escuras?

Permitensen poner, i es bien ponellos,

como trofeos de la Iglesia: i ella

con esto muestra, que se sirve d'ellos.

Assi esta dama ilustre, cuanto bella,

de la Poesia, cuando se compone,

en onra de su Dios, que pudo hazella:

Con su divino espíritu dispone

de los Dioses antiguos, de tal suerte,

qu'a Cristo sirven, i a sus pies los pone. (vv. 739-756)

Esta concepción de la poesía, que no sólo en su origen sino en sus formas imita el orden de lo divino, alcanza su punto culminante en la justificación del empleo retórico de la figura del concepto, cuando se afirma que los mismos ángeles se expresan en lenguaje figurado, por ser éste más espiritual y discreto:

I como la Poesia al ombre vino

d'espiritus angélicos perfetos,

que por concetos hablan de contino:

Los espirituales, los discretos

sabran más de Poesía, i será ella

mejor mientras tuviere más concetos. (Vv. I24-I29).

En esta línea de espiritualización de la poesía, y en consonancia con la teologización del arte antes mencionada, la condición de Poeta adquiere un estatuto moral y ejemplificador:

I assi el que fuere dado a todo vicio

Poeta no será, pues su instituto

es deleytar: i dotrinar su oficio.

Que puede dotrinar un disoluto?

que pueden deleytar torpes razones?

pues solo està el deleyte do está el fruto. (vv. 289-294)

LA VOZ DE LA SIBILA

En los últimos versos del poema, la voz enunciadora apela a Mexía en estos términos: 
I pues eres mi Delio, ten la rienda

al curso, con que buelas por la cumbre

de tu esfera, i mi voz, i metro enmienda,

para que dinos queden de tu lumbre. (vv. 805-808)

La identificación entre Mexía y Apolo y la invocación para que enmiende el metro y la voz del sujeto poético, instalan nuevamente el tópico de la voz femenina inspirada por influjo de una divinidad, masculina. Es por ello que una crítica como Carmen Perilli ha llegado a la conclusión de que el Discurso no subvierte las categorías masculinas de un mundo jerarquizado: la poetisa anónima es al poeta varón, Mexía, como América a Europa y la doble heterogeneidad - geográfica y de género - es sometida a la cultura hegemónica. Sin embargo, afloran en el Discurso un registro cultural y una celebración de la productividad poética americana, una reflexión metapoética que ha sido señalada como un hito seminal del pensamiento crítico colonial. Y en una dialéctica de saber universal y memoria local, el tópico renacentista de la defensa de la poesía es reescrito como contrapunto letrado de la épica de las armas en América:

I vosotras Antarticas regiones

tambien podeis teneros por dichosas,

pues alcançais tan celebres varones:

Cuyas plumas eroicas, milagrosas

darán, i an dado muestras, como en esto

alcançais voto, como en otras cosas. (vv. 496-5oI)

El poema destaca el heroísmo de esas plumas antárticas, "milagrosas" por el servicio prestado a la fe pero también por lograr lo que para el hierro no era del todo posible, como la conquista del Arauco. Ello nos habla de la eficiencia simbólica de la poesía, de su lugar en lo que hoy llamaríamos la construcción del imaginario colonial.

Por último, el hecho de que sea una voz femenina la encargada de articular este elogio y defensa del orden poético, doblemente reflexivo por concretarse en un poema, nos pone frente a una nueva versión de esa Eva que, si alguna vez había empujado a Adán de la intemporalidad mítica del paraíso al devenir de la historia, no había renunciado por ello a la tarea de entonar su canto y "hazer, con artificio / nuestra imperfeta vida más perfeta", sintetizando así el programa moral y político de un imperio cristiano con la erudición y la elocuencia humanistas. Como las Sibilas que la tradición cristiana y el neoplatonismo habían recreado y revalorizado, por el servicio prestado a la fe cristiana desde las tinieblas de un mundo 
pagano, el sujeto del $D L$ trata de encontrar su lugar en el concierto de las voces ordenadoras del Nuevo Mundo, profetizando "hazañas" de las armas y las letras y colaborando en la cristianización del arte y las costumbres. En efecto, el neoplatonismo del siglo XVI veía en las imágenes de Apolo y las Sibilas una prefiguración, en el mundo pagano, del origen de la poesía entendido en clave cristiana: un don de Dios sólo pasible de ser otorgado a sujetos eruditos y moralmente dignos. En sintonía con ello, la voz enunciadora del $D L$ se arroga la misión de ser ese sujeto, desde donde se profiere la palabra poética que es, en consonancia con esta doctrina, otra forma del "sacro ... canto" (v. 446). El anonimato del poema puede, asimismo, entenderse en correspondencia con la empresa en que se ha embarcado este sujeto poético: la desaparición del nombre propio equivale, de algún modo, a la disolución del cuerpo de la sibila de Cumas quien, recordemos, le había explicado a Eneas cómo se vería consumida por el tiempo y su quehacer profético, hasta convertirse en sólo una voz: "para todos invisible, no obstante, por mi voz / seré reconocida, porque los hados me dejarán la voz" (Ovidio, Metamorfosis..., XIV, vv. I47 - 153, 515). Una misión de esta naturaleza, tan heroica como divina, ofrecía una razón más que suficiente para que el editor del Parnaso Antártico presentase a la anónima autora del $D L$ como una "heroica dama", digna de acompañar a las figuras ejemplares de Ovidio.

Consejo Nacional de Investigaciones Científicas y Técnicas (CONICET)/ Universidad Nacional de Mar del Plata (UNMDP)

NOTAS

I La segunda parte quedaría inédita. Está centrada en sonetos que elogian las estampas sobre la vida y la pasión de Cristo, pintadas por el jesuita Jerónimo Natal en Potosí, Bolivia. Raquel Chang-Rodríguez menciona una, hasta hoy perdida, Tercera Parte del Parnaso Antártico (67).

2 Para las citas, seguimos la edición del Discurso en loor de la poesía preparada por Antonio Cornejo Polar y revisada por José Antonio Mazzotti, que confrontamos con las ediciones de Tauro y de Calderón de Cuervo. De aquí en adelante, haremos referencia al texto como $D L$.

3 El poema concluye con un cuarteto, para que no quede ningún verso suelto.

4 También se nutrieron las defensas de la poesía del De oratore y del $D e$ inventione. Recordemos que el Pro Archia fue redescubierto por Petrarca y que el Cardenal Bembo, en su epistola De imitatione, había canonizado a Cicerón y Virgilio como modelos de las letras latinas dignos de ser imitados por los 
humanistas. Según el seguimiento del mercado editorial de la época consignado por Antonio Cornejo Polar, Cicerón era el autor más solicitado en todo el territorio americano, seguido de Virgilio. Siguiendo a Menéndez y Pelayo, el crítico peruano coincide en que varios versos del $D L$ son una paráfrasis de este texto de Cicerón, aunque con el agregado de una dimensión religiosa (24; II5). Para el impacto de este texto ciceroniano y de sus exégetas y comentaristas en la cultura del humanismo renacentista, remitimos al estudio de Antonio Camarero citado en la bibliografía.

5 Se refiere puntualmente a las de Sánchez de Lima, El arte poético en Romance Castellano (1580), primer libro español que recoge las doctrinas poéticas de la escuela italiana; García Rengifo, Arte poética española (1552), quien defiende el origen divino de la poesía y coloca a Adán en el lugar del primer poeta; López Pinciano, Philosophia Antigua Poetica, aunque su visión de la poesía es más aristotélica que la que encontramos en el $D L$, y El Cisne de Apolo de Luis Alfonso de Carballo. Por su parte, Cisneros se refiere al $D L$ como la "primera preceptiva escrita en América" (2OI).

6 De hecho, hubo algunas versiones castellanas previas de las Heroidas, basadas tanto en códices donde sólo figuraba el texto latino como en otros, donde el texto fuente estaba acompañado de glosas, introducciones y comentarios. A partir de estos últimos se tradujo la obra ovidiana en la Edad Media al castellano. Estos epígrafes colaboraron en la cristianización de Ovidio, porque en ellos se ofrecía una interpretación de los mitos recuperados por Ovidio que los ponía al servicio de la moral cristiana. Entre esos textos, se destacaron diversas versiones, en prosa y verso, del Ovidius moralizatus, por ejemplo, donde la alegoría permitía asignarle un sentido teológico a la mitología (Alvarado Teodorika, nota 29).

7 El destierro también es un eje compositivo del alegato ovidiano In Ibin, que sigue a la traducción de las Heroidas.

8 Sólo aparece la contraparte de las voces masculinas en las epístolas de París a Elena y de Aconcio a Cidipe. La idea de diálogo es consustancial a la de discurso, que el Diccionario de Autoridades define, en una de sus acepciones, como "razonamiento, plática o conversación ponderada y dilatada, sobre alguna materia" (Tomo III, I732).

9 Por razones de legibilidad, citamos las Heroidas por la edición de i884.

IO Todavía en el siglo XIX se seguía publicando la traducción de Mexía, como lo prueba la edición madrileña de I884 de Las Heroidas. De todos los paratextos originales, en esa edición, sólo perviven el prólogo de Mexía y la biografía de Ovidio.

II Ya Alberto Tauro señalaba lo inapropiado de identificar a la Clarinda mencionada en el texto con la autora del poema (26), mientras que Jorge 
Cornejo Polar considera que Ricardo Palma le dio el nombre de Clarinda a la autora del discurso, "desaprensivamente" (39).

I2 Notemos, en consonancia con lo señalado por Sabat de Rivers, que es omitido el rol de Eva en relación con el pecado original (Antes de Juana Inés). Por otro lado, la Eva como voz auxiliar de la poesía producida por un sujeto masculino tiene un correlato en la mención a Pola, la esposa de Lucano, de quien se menciona el hecho de que fue la que pulió los últimos cantos de la Farsalia después de la muerte de su marido (v. 434).

I3 Para la información que sigue, ver Buisel, Daremberg y Saglio (entradas "Apollo" y “Divinatio"), Ovidio Metamorfosis, San Agustín (Libro X, capítulo XXVII y Libro XVIII, capítulo XXIII), Yates (especialmente los capítulos I y II, "Hermes Trismegisto" y "El Pimander de Ficino y el Asclepius", 17-62).

I4 En el libro XVIII de La Ciudad de Dios, San Agustín afirma haber tenido acceso a un códice griego donde estaban transcriptas las profecías de la mencionada Sibila, en el cual las palabras iniciales de los versos formaban (en griego) el acróstico: Jesucristo, Hijo de Dios Salvador. Los versos cuyas letras iniciales formaban ese significativo acróstico eran los que describían un evento equiparable tanto a la idea de fin de los tiempos como del consecuente Juicio Final. Para reforzar sus argumentos, el santo de Hipona mencionaba un pasaje de Lactancio, aunque con las reservas debidas a la imposibilidad de confiar enteramente en la preservación fiel de las palabras sibilinas por parte de los diversos copistas o transcriptores. San Agustín inicia el capítulo aludiendo a la Sibila de Eritrea, pero más adelante explica que algunos creen que se trataba de la misma Sibila de Cumas, y tampoco puede determinar si esa Sibila existió en tiempos de Rómulo o de la Guerra de Troya. Lo que es indudable, para este

padre de la Iglesia, es que dicha Sibila merece ser un miembro de la "Ciudad de Dios", por el mensaje profético que se le asigna. La asociación de la Sibila aunque no claramente individualizada - con la profecía del Juicio Final se encuentra presente también en el himno latino tardomedieval Dies Irae, donde la Sibila, junto al profeta David, sería testigo del fin de los tiempos.

I5 El caso de las Sibilas que decoraban la mansión del Deán de Puebla de los Ángeles, en México, pone en escena a unas originales Sibilas amazonas (ver Buisel).

I6 Cabe recordar que, por razones etimológicas, el nombre "sibila" remite a los bosques y las selvas, haciendo de la sibilas el equivalente a las voces proféticas que nacían de las grutas o cuevas en tiempos de religiones animistas. De allí la asociación de las sibilas con las ninfas. El culto de las sibilas habría nacido como fusión de los vestigios del culto arcaico de las Ninfas y del culto de Apolo. Manto, por otra parte, es una figura que tiene un equivalente en una versión de la sibila proveniente del Asia Menor (Daremberg y Saglio, "Divinatio" 313-3I4).

I7 Para Antonio Cornejo Polar, el $D L$ se ubica en una tradición de pensamiento platónico-agustiniano, heredero de los poetas trovadorescos, del Marqués de 
Santillana, de Fray Luis de León, de Rengifo y de Carballo (79-80). El mismo Cicerón sostenía que los poetas estaban inspirados "por una especie de soplo divino" y que merecían el calificativo de "sagrados" que les había puesto Enio, "porque parecen habernos sido confiados como por cierto don y regalo de los dioses" (64).

I8 La cuestión de la localización poética no es menor si se tiene en cuenta el discurso Pro Archia de Cicerón, una de las fuentes del $D L$, un texto que había sido redescubierto por Petrarca, en Lieja, en r 333 y que fue difundido desde Italia, colaborando en la nueva apropiación de la tradición ciceroniana, esta vez, por el humanismo renacentista. El ejercicio de la poesía es, precisamente, uno de los principales valores en los que Cicerón sustenta la defensa de este poeta de origen griego que el orador defendía en su reclamo de ciudadanía romana, en el juicio que tuvo lugar en el año 62 a. C. y que dio lugar a ese texto en el que, para defender a Arquías, defendía el rol cívico de la poesía y los poetas.

I9 Notemos, respecto de esta imposibilidad, casi dogmática, la similitud con el planteo epistemológico de los límites del conocimiento del Primero Sueño de Sor Juana Inés de la Cruz.

20 El problema del arte como parte de un ocio productivo, es expuesto con claridad en un pasaje del Pro Archia en el cual Cicerón defiende la utilidad de la poesía para la república: “...Avergüéncense todos los que se han encerrado en su dedicación literaria de tal manera que no son capaces de aportar utilidad alguna de ella para el bien común ni ofrecerla a la luz y vista de todos..." (58). Refiriéndose a las letras, dice que "esta dedicación espiritual [es] la más digna de un hombre y de un ciudadano libre. Pues las otras no son propias de todo momento, edad ni lugar; en cambio estos estudios educan a la juventud, deleitan a la ancianidad, prestigian la prosperidad, ofrecen un refugio y consuelo a la adversidad, son un placer en el hogar, no estorban fuera de él, velan de noche con nosotros, nos acompañan en los viajes y en nuestra vida en el campo" (62).

OBRAS CITADAS

Alvarado TEOD ORIKA, TATIANA. "Mexía de Fernangil: lector y creador de las Heroidas ovidianas. Itinerario de un traductor". La clé des langues (2016): S. pag. Web.

B ar Re Ra, trin id ad. "La Primera parte del Parnaso Antártico de Diego Mexia de Fernangil, Sevilla, I608”. Andalucía y América en el Siglo XVII: Actas de las III Jornadas Andalucía y América. Coord. Bibiano Torres Ramírez y José J. Hernández Palomo. La Rábida: CSIC/Escuela de Estudios Hispanoamericanos/ Universidad Hispanoamericana Santa María de la Rábida, I985. 213-229.

-. "Una voz femenina anónima en el Perú colonial, la autora del Discurso en loor de la poesía". Mujer y cultura en la colonia hispanoamericana. Ed. Mabel 
Moraña. Pittsburgh: Instituto Internacional de Literatura Iberoamericana, I996. III-I22.

B E L L I N I, G I USE P PE. "Il secolo XVI". Storia delle relazioni letterarie tra l'Italia e l'America di lingua spagnola. Milano: Cisalpino-Goliardica, I982. I-38.

B U ISEL, MARÍA DEL IA. “Aspectos de la tradición clásica en América: Sibilas y Triunfos en la Casa del Deán de Puebla de los Ángeles (México)". Auster I2 (2007): IO3-I3I.

CALDER Ón DE CUERVo, ELEnA. “Introducción. La Filosofía poética en los virreinatos americanos". Discurso en loor a la poesía. Ed. Elena Calderón de Cuervo. Buenos Aires/Mendoza/Santander: Facultad de Filosofía y Letras de la Universidad Nacional de Cuyo/Nueva Hispanidad Académica, 2003. 9-94. Cam a Re R o, a n t o n o. "Introducción”. Cicerón. Defensa del poeta Arquías. Trad. Antonio Camarero. Bahía Blanca: Universidad Nacional del Sur, 1965.5-47.

Cas t a ny pRADo, Be Rna t. Las 'Heroidas' de Ovidio, en la traducción de Diego Mexía de Fernangil (1608). Alicante: Biblioteca Virtual Miguel de Cervantes, 20 I2.

C H A N - R O D íg UE z, RA que l. "Ecos andinos: Clarinda y Diego Mexía en la Primera parte del Parnaso Antártico (1608)”. Calíope 9, I (2003): 67-80.

Cice ró n. Defensa del poeta Arquías. Trad. Antonio Camarero. Bahía Blanca: Universidad Nacional del Sur, 1965.

cisne ros, luis jaime. "Para un estudio del Discurso en loor de la poesía". Discurso en loor de la poesía. Eds. Antonio Cornejo Polar y José Antonio Mazzotti. Lima/Berkeley: Centro de Estudios literarios Antonio Cornejo Polar/ Latinoamericana editores, 2000. 163-215.

c o lom Bí-monguió, A I ICIA DE. "El Discurso en loor de la poesía, carta de ciudadanía del humanismo sudamericano". Del exe antiguo a nuestro nuevo polo. Una década de lírica virreinal (Charcas I602-I6I2). Berkeley: Centro de Estudios Antonio Cornejo Polar/Latinoamericana Editores, 2003. 23-54. CORNEJO POLAR, ANTONio. "Primera parte. El contexto" y "Segunda parte. El texto. Estudio”. Discurso en loor de la poesía. Estudio y edición. Eds. Antonio Cornejo Polar y José Antonio Mazzotti. Lima/Berkeley: Centro de Estudios literarios Antonio Cornejo Polar/ Latinoamericana editores, 2000. II-I3O.

CORNEJO POLAR, JORGE. "Literatura peruana. Época colonial" Literatura Peruana. Siglo XVI a Siglo XX. Eds. Antonio Cornejo Polar y Jorge Cornejo Polar. Lima: Centro de Estudios Literarios Antonio Cornejo Polar (CELACP)/ Latinoamericana Editores, 2000. 9-130.

CURTIUS, ERNST Ro BERT. "La teoría teológica del arte en la literatura española del siglo XVII". Literatura europea y edad media latina. Trad. Margit Frenk Alatorre y Antonio Alatorre. Tomo II. México/Buenos Aires: FCE, I955· 760-775.

DAREMBERG, CHARLES Y EDMOND SAGLIO. Dictionnaire des antiquités grecques et romaines d'aprés les textes et les monuments. Io vol. Paris: Hachette, I877-919. REA l ACAde mia esPaño La. Diccionario de Autoridades. Web. 
Discurso en loor de la poesía. Ed. Alberto Tauro. Esquividad y gloria de la Academia Antártica. Lima: Huascarán, 1948. 43-91.

Discurso en loor de la poesía. Ed. Antonio Cornejo Polar. Lima/Berkeley: Centro de Estudios Literarios Antonio Cornejo Polar/Latinoamericana Editores, 2000.

Discurso en loor a la poesía. Ed. Elena Calderón de Cuervo. Buenos Aires /Mendoza/ Santander: Facultad de Filosofía y Letras de la Universidad Nacional de Cuyo / Nueva Hispanidad Académica, 2003.

LOHMANN VILLENA, GUILLERMo. "Huellas renacentistas en la literatura peruana del siglo XVI". La tradición clásica en el Perú virreinal. Ed.Teodoro Hampe Martínez. Lima: UNMSM, 1999. I15-127.

mazzot ti, josé a n o nio. "El Discurso en loor de la poesía y el aporte de Antonio Cornejo Polar". Discurso en loor de la poesía. Ed. Antonio Cornejo Polar y José Antonio Mazzotti. Lima/Berkeley: Centro de Estudios literarios Antonio Cornejo Polar/ Latinoamericana editores, ix-xxxix.

m exíA, di g go. Primera parte del Parnaso Antártico de Obras amatorias, con las 2 I epístolas de Ovidio, y el In Ibin, en tercetos. Sevilla: Alonso Rodríguez Gamarra, 1608.

MORAÑA, MABEL. "Fundación del canon: hacia una poética de la historia en la Hispanoamérica colonial". Revista de Crítica Literaria Latinoamericana 22.43-44 (1996): 17-43.

-. Viaje al silencio. Exploraciones del discurso barroco. México: UNAM, 1998. ovidio. Las heroidas. Trad. Diego de Mexía. Madrid: Luis Navarro, I884.

-. Las metamorfosis. Ed. y trad. Emilio Rollié. Buenos Aires: Losada, 2012. PÉrez-B lanco, L uCREcio. "Discurso en loor de la poesía. El otro lazarillo éticoestético de la literatura hispanoamericana del siglo XVII”. Quinto centenario I6 (1999): 209-237.

PERILLI, CARMEN. "Los enigmas de una dama y la fundación de la crítica latinoamericana: el Discurso en loor de la poesía". Etiópicas I (2004-2005): 130I43.

RAmA, Án GEL. La ciudad letrada. Prólogo Carlos Monsiváis. Santiago de Chile: Tajamar, 2004.

RIVERS, e LíAS L. "La alabanza de la poesía". Revista de Crítica Literaria Latinoamericana 22.43- 44 (1996): II-I6.

ROSE, SO NIA V. "Hacia un estudio de las élites letradas en el Perú virreinal: el caso de la Academia Antártica". La ciudad letrada, de la conquista al modernismo. Ed. Jorge Myers. Vol. 2. Buenos Aires: Katz, 2008. 79-93.

SABAt DE Rivers, Georgina. "Antes de Juana Inés: Clarinda y Amarilis, dos poetas del Perú colonial". Estudios de literatura hispanoamericana: Sor Juana Inés de la Cruz y otros poetas barrocos de la colonia. Barcelona: Promociones y

Publicaciones Universitarias, 1992. 
-. "Las obras menores de Balbuena: erudición, alabanza de la poesía y crítica literaria". Revista de Crítica Literaria Latinoamericana 22. 43-44 (1996): 89-IOI. san a gus tín. La Ciudad de Dios. Trad. Santos Santamarta del Río y Miguel Fuertes Lanero. Biblioteca de Autores Cristianos/ Federación Agustiniana Española. T AU Ro, Al B ER T o. Esquividad y gloria de la Academia Antártica. Lima: Huascarán, I948.

yates, F RAnCes a. Giordano Brunoy la tradición hermética. Trad. Domènec Bergadà. Barcelona: Ariel, 1983. 